PATRICK C. MEIRICK ${ }^{1}$

\title{
Topic-Relevant Reference Groups and Dimensions of Distance
}

\section{Political Advertising and First- and Third-Person Effects}

This article argues for using topic-relevant reference groups in examining first- and third-person effects. It also proposes using topic-relevant dimensions of distance to assess relationships not only between self and target groups but also relationships both have with communicators. The study showed 2000 presidential primary ads from Al Gore and George W. Bush to a combined sample of student and nonstudent partisans $(\mathrm{N}=140)$. Participants perceived greater effects on the out-group and on the general public then on themselves for ads from the out-group candidate. A third-person effect was also observed for ads from the in-group candidate in self-in-group and self-public comparisons. The only first-person effect was found for the self-out-group comparison of responses to the in-group candidate ads. Selfcandidate political distance, an analogue of message desirability, was negatively related to perceived effects on self and target groups, whereas self-group and group-candidate distance measures showed only sporadic relationships to perceived effects.

Keywords: third-person effect; first-person effect; social distance; reference groups; self-enhancement

In a memorable phrase defining third-person effect, Davison (1983) proposed that people think the media's greatest impact "will not be on 'me' or 'you' but on 'them'-the third persons" (p. 3). This formulation explicitly recognizes social distance as a key variable in its suggestion that perceived effects will be greater for third persons (them) than for second persons (you). Davison suggested that "the concept of reference groups may prove useful in

COMMUNICATION RESEARCH, Vol. 31 No. 2, April 2004 234-255

DOI: 10.1177/0093650203261514

(c) 2004 Sage Publications 


\section{Meirick • Dimensions of Distance}

explaining the third-person effect. Are people 'like me' or 'different from me' seen as being more affected by persuasive messages?” (p. 12).

The concept of reference groups and the possible dimensions of likeness and difference from the self have gone largely unexplored in third-person effect research. Many studies ask their participants for estimates of effects on generalized "other people." Those using social distance as a variable often operationalize it as levels of increasing generality or geographical distance, so that the participant compares message effects on herself with effects on others in her university, city, state, and country (e.g., Cohen, Mutz, Price, \& Gunther, 1988; White, 1997). It is a reasonable all-purpose substitute. But certain topics, such as race (Neuwirth, Frederick, \& Mayo, 2002), gender (Wan, 2002), and politics (Duck, Hogg, \& Terry, 1995) all but beg for a conceptualization of social distance using topic-relevant dimensions of difference based on in-groups and out-groups.

Even if we conceptualize social distance in this way, we are still making a priori assumptions about the distance between individual respondents and target groups. To remedy this, Eveland, Nathanson, Detenber, \& McLeod (1999) used individual measures of respondents' closeness to reference groups. The logic of topic-relevant dimensions of difference could be applied to this remedy as well. When dealing with political topics, for instance, instead of assessing general closeness or distance, one could assess the difference between the self and a target group in perceived political ideology.

Moreover, the distance between the self and the target group is not the only one that needs to be considered. Remember that there is a communicator (sometimes explicitly, other times only implied in the content of the message) in the equation as well. That means we would do well to think about the distance between the self and the communicator and also the perceived distance between the communicator and the target group.

To some extent, the research on message desirability can be seen as addressing the question of distance between the self and the communicator. Messages from trusted sources are seen as more desirable (Cohen et al., 1988; Gunther, 1991), as are ones from favored political candidates (Cohen \& Davis, 1991; Duck et al., 1995). People perceive relatively greater influence on themselves from such messages, which attenuates or reverses the third-person effect. The reversal appears to implicate self-enhancement and motivated processing in third- and first-person effects (Meirick, 2002; Neuwirth et al., 2002).

The question of perceived distance between target groups and the communicator has received considerably less attention. If target-communicator distance has any bearing on the third-person effect, it would be because the perceiver's estimate of a message's effects on others was based on the perceived 


\section{COMMUNiCATion ReSEARCH • April 2004}

relationship between the target group and the communicator. A similar idea is at the core of the target corollary (Eveland et al., 1999), which states that perceived effects on target groups are influenced by perceived exposure-and perceived attention (Neuwirth \& Frederick, 2001)—of that group to the communication.

This article will explore the political dimension of likeness and difference in the context of perceived responses to political advertising. In doing so, it will consider distance not just between self and target groups but also between self and communicator and target groups and communicator.

\section{Traditional Social Distance:}

\section{Self to Target Group}

Third-person effect research often has shown that the greater the social distance between the self and target group, the greater the gap in perceived impact. A number of studies have lent support to the importance of social distance in third-person effect. Cohen et al. (1988) found that perceived impact of a defamatory news story was smallest on "self," increased for "other Stanford students," increased again for "other Californians," and was greatest for "public opinion at large." White (1997) found a similar (but imperfect) pattern for self, local students, students at other universities, and other state residents. Gibbon and Durkin (1995) found that same pattern of ascending impact from self to family to neighbors to other state residents to other Australian citizens to others in general.

The conceptualization of social distance in these studies is similar. Each step in social distance entails a step up in social organization, each step up becoming more general and incorporating more subordinate components. It is as though these groups are conceived of as a series of concentric circles that grow outward with the self at the center, so that each increment of social distance (family, neighborhood, state, country) completely contains all smaller increments and is completely contained by the next larger increment. It is nearly analogous with geographic distance; in fact, Cohen and Davis (1991, p. 682) chose those exact words to describe the variable used in Cohen et al. (1988).

The conceptualization of social distance as a set of nested social (or geographic) levels may not always be highly relevant or appropriate. This is particularly true in contexts where social groups are seen as opposed. In such cases, an alternate conceptualization of social distance would see social groups as adjacent circles-in-groups and out-groups. Here, the distinction between "you" and "them" as Davison (1983) discussed them is clear- 


\section{Meirick • Dimensions of Distance}

members of the same in-group are you-or we-whereas members of outgroups are them. This in-group-out-group approach toward social distance echoes the "hostile media phenomenon" work of Vallone, Ross, and Lepper (1985) and Perloff (1989) in their examination of Israeli and Palestinian partisans' perceptions of the effect of news reports about the 1982 war in Lebanon. More recently, Wan (2002) explored gender-based reference groups in the influence of magazine ads on body image, while Neuwirth and Frederick (2002) used race-based reference groups in examining the influence of news depictions of a minority neighborhood. The reference-group approach seems well suited for political contexts as well: Those of the same party are the ingroup, whereas those of the opposing party are the out-group (Duck et al., 1995).

The reference-group approach also helps to draw a link between social distance and self-enhancement, the tendency to hold what Taylor and Brown $(1988,1994)$ call “positive illusions" about one's own traits, abilities, and prospects. Self-enhancement is the Western self's chief mechanism for maintaining self-esteem and is one of the hypothesized processes underlying the thirdperson effect (Gunther \& Mundy, 1993; Hoorens \& Ruiter, 1996; Meirick, 2002; Perloff, 1999). The linkage comes from the fact that membership in reference groups can play an important role in the self-concept. According to social identity theory (Tajfel \& Turner, 1979) and self-categorization theory (Turner, 1985), people tend to highlight their similarities to in-group members and highlight their differences with out-group members. Then, when they make group comparisons, they tend to favor the in-group as a way to enhance self-esteem. Duck et al. (1995) draw the connection between selfenhancement and group membership in the context of the third-person effect, in which media influence is typically seen as undesirable:

To the extent that the comparison others are judged as outgroup members, they would be contrasted to the perceiver's identity, evaluated negatively, and represented unfavourably - as relatively vulnerable to media influence. In contrast, to the extent that comparison others are judged as ingroup members, they would be assimilated to the perceiver's identity, evaluated positively and represented favourablyas relatively invulnerable to influence. (p. 198)

The target groups that respondents in this study were asked about, therefore, were based in part on party identification: Democrats, Republicans, and the general public. Depending on the respondent's own party identification, the parties can then be identified as in-groups and out-groups. Although it is neither an in-group or an out-group, the public is retained as a target 


\section{COMMUNiCATion ReSEARCH • April 2004}

group in this study because it allows for a point of contact with most other third-person effect research, where in-groups and out-groups are rarely used as "others," but the general public often is. Second, the public should fall between Democrats and Republicans on most people's perceptions of political affiliation and thereby provide more of a continuum for perceptions of effects.

Distance between the self and target groups also can be measured and used as an individual-level variable (Eveland et al., 1999). This study will adopt a common measure in political science, the perceived distance between one's own location on the liberal-to-conservative continuum and that of the political parties (Downs, 1957).

\section{Message Desirability and Distance \\ Between Self and Communicator}

Seeing the self and the in-group as relatively invulnerable to media influence makes sense when media messages and their influence are seen-as they often are-as undesirable. But when a message is perceived as desirable or "smart to be influenced by" (Gunther \& Mundy, 1993), the third-person effect is minimized (Gunther \& Mundy, 1993; Innes \& Zeitz, 1988) or reversed into a first-person effect (Chapin, 2000; Duck et al., 1995; Hoorens \& Ruiter, 1996; Meirick, 2002; White, 1997; White \& Dillon, 2000). Under the logic of selfenhancement, it may be seen as smart and in one's self-interest to take desirable messages under advisement. People may then perceive themselves and those close to them as more receptive to these positive media messages than other people, who are not seen as so astute and open-minded. However, perceptions of control and self-determination also are important to self-esteem (Jones, 1979), and acknowledging influence, even from a desirable message, runs counter to such perceptions (Gunther \& Mundy, 1993). This may be why the first-person effect is not as robust as the third-person effect.

Still, first-person effects have been found for messages that are broadly considered prosocial (and are operationalized as such on an a priori basis), such as public service announcements or news stories about organ donation (White \& Dillon, 2000), seatbelt use (Gunther \& Mundy, 1993), and tanning safety (Hoorens \& Ruiter, 1996). But of more interest for the purposes of this article are instances where message desirability more clearly reflects a degree of affinity with the perceived communicator. Third-person effects are smaller when reports come from a trusted source (Cohen et al., 1988; Gunther, 1991). Even more to the point, first-person effects have been found for political messages in which the communicator's identity is clear and his partisanship is highly important to perceived desirability; the same 


\section{Meirick • Dimensions of Distance}

messages are judged desirable by those in one party and undesirable by the opposing party. Cohen and Davis (1991) found that a candidate's supporters thought they were more swayed by his ad than other people would be, whereas they said they would be unswayed by an ad from the opponent. Duck et al. (1995) found that members of an Australian party judged themselves and their fellow party members to be more influenced than members of other parties by material favoring their party.

These findings suggest that message desirability in political contexts can be serviceably operationalized as whether the communicator is of the same party (or in-group) as the respondent. This basic indication of smaller or greater distance between self and communicator will serve the purposes of analysis of variance. But as with the distance between self and target, the distance between self and candidate can be measured as an individual-level variable, and this study does so not only with the self-to-candidate ideology difference score but with candidate preference and candidate favorability ratings as well as party membership.

\section{Inferred Distance:}

\section{Communicator to Target}

The idea that the third-person effect is based on a self-enhancing out-group bias was challenged by Eveland et al. (1999), who simultaneously expanded conceptions of social distance and argued persuasively against their significance. First, they presented multiple conceptions of social distance: different levels of generality, age, and education for target groups, as well as a direct measure of perceived similarity to the target groups. They then demonstrated the primacy of perceived frequency of exposure as a contributor to the third-person effect over perceived similarity. But to dismiss completely social distance in favor of perceived exposure would be premature. In their second study, Eveland et al. found that when they asked people to assume equal exposure for different target groups, the third-person effect remained significant, and perceived effects increased as social distance increased in five of the six comparisons. Moreover, exposure to certain kinds of media messages is not likely to vary, or even be perceived as varying, between some target groups. Arguably, political ads are a good example of this. Candidates of both parties tend to advertise during the evening news; people of both parties watch the news in roughly equal numbers. ${ }^{2}$

The best argument for the relevance of target-communicator distance can be derived from an argument at the core of the target corollary itself: the idea that people "observe or infer a relationship between certain types of media 


\section{COMMUNiCATion RESEARCH • April 2004}

content and certain types of people. For instance, most people could guess that romantic comedies are more popular among women, whereas action movies are more popular among men" (Eveland et al., 1999, p. 281). That is, their estimates of message exposure for others are based on real-world knowledge and expectations about target groups. By the same reasoning, we might expect people to have real-world knowledge and expectations about how receptive different groups are to certain media messages, even if exposure to those messages did not vary between those groups. If so, relevant dimensions of social distance (e.g., the partisanship of target groups in considering messages from politicians) should play a role in estimates of receptivity to different messages. Just as the distance between the communicator and the self can be seen as an indicator of the message's desirability and the self's receptivity, the perceived distance between the target group and the communicator may be an indicator of the target group's perceived receptivity to the message. In a political context, these distances can be derived from the perceived locations of the groups and the candidates on the ideological continuum.

\section{Hypotheses}

In line with previous work on social distance, we would expect to see thirdperson effects for undesirable (out-group) messages for two very different (but in this case converging) reasons: It may be self-enhancing to believe that those more distant from the self will be more affected by an undesirable message, and/or respondents may recognize that the out-group candidate's messages will be more appealing to out-group members because of their political closeness to him.

Hypothesis 1a: Ads from the out-group candidate will be perceived to have greater effects on others than on the self.

Hypothesis 1b: Perceived effects of ads from the out-group candidate will increase as the target group becomes more politically distant from the self.

Ads from the in-group candidate, however, should produce first-person effects, because it may be self-enhancing to be receptive to desirable messages (messages from a candidate who is politically close) and/or because respondents may recognize the greater political distance that the in-group candidate has from more distant target groups. 


\section{Meirick • Dimensions of Distance}

Hypothesis 2a: Ads from the in-group candidate will be perceived to have greater effects on the self than on others.

Hypothesis 2b: Perceived effects of ads from the in-group candidate will decrease as the target group becomes more politically distant from the self.

Next, we must consider hypotheses concerning alternative conceptions of social distance. Of these, we first address the directly measured political distance between self and target groups. We posit hypotheses consistent with the social distance corollary and with findings on message desirability such that greater distance from the self is associated with greater effects for undesirable messages and smaller effects for desirable messages:

Hypothesis 3a: Political distance between self and target group will be positively related to perceived effects of the out-group candidate's ads on the target group.

Hypothesis 3b: Political distance between self and target group will be negatively related to perceived effects of the in-group candidate's ads on the target group.

The distance between self and communicator is analogous with message desirability, and any relationships we observe would likely reflect selfenhancement and in-group-out-group dynamics rather than knowledge and expectations of the receptiveness of target groups. With greater self-tocandidate distance, we would expect to see smaller effects on the self and the in-group, whereas the closer a respondent is to the candidate, the greater the perceived effects on self and close others will be.

Hypothesis 4a: Political distance from self to candidate will be negatively related to perceived effects on self.

Hypothesis 4b: Political distance from self to candidate will be negatively related to perceived effects on the in-group.

The reverse should apply to out-groups, which should be contrasted unfavorably with the self. The more distant a candidate is from the self, the less desirable the message and the greater the effects we would expect for the outgroup (Duck et al., 1995). We would also expect the candidates close to the self to have desirable messages, which the out-group (by unfavorable contrast with the self) would not be astute enough to take under advisement.

Hypothesis 4c: Political distance from self to candidate will be positively related to perceived effects on the out-group. 


\section{Communication ReSEARCH • April 2004}

As for the public, there is conflicting theory and evidence as to the influence of self-to-communicator distance. On one hand, the general public could be conceived of as a very high level of generality and thus distant from the self, and the social distance corollary would then suggest that this group would be most distinct from the self in their perceived reactions. Moreover, the hostile media phenomenon (Perloff, 1989) suggests that partisans will believe neutral viewers to be swayed toward the out-group. If so, we would expect a positive relationship between self-communicator distance and effects on the public. On the other hand, the false consensus effect (Marks \& Miller, 1987) would suggest that people tend to assume that their own opinions and situational responses are more common than they really are and generalize to most people (but not out-groups; see Clement \& Krueger, 2002). This would suggest a negative relationship between self-communicator distance and perceived effects on the public, much as there is for the self and the in-group. To make the matter more complex, recent work by Gunther and Christen and their colleagues (Christen \& Gunther, 2003; Gunther \& Christen, 2002; Gunther, Christen, Liebhart, \& Chia, 2001) suggests that although people tend to project their own viewpoints on to the public, this tendency can be countered by the hostile media phenomenon. The conflicting evidence poses this question:

Research Question 1: What will be the relationship between self-candidate distance and perceived effects on the public?

Finally, there is the matter of perceived candidate-to-target-group distance. This can be seen as a measure of a target group's receptiveness to the candidate's message based on perceptions of the ideological compatibility between the two.

Hypothesis 5: Candidate-to-target-group distance will be negatively related to perceived effects of the candidate's ad on the target group.

Given these three conceptions of political distance, there remains an important question:

Research Question 2: How much variance in perceived effects on target groups does self-to-candidate, self-to-target-group, and candidate-totarget-group distance account for? 


\section{Meirick • Dimensions of Distance}

\section{Method}

Data for this study were collected during the 2000 presidential primaries from three groups: 30 (predominantly Democratic) members of the League of Women Voters, 23 attendees at a Republican precinct caucus, and 129 undergraduate communication students. To accommodate in-group and out-group classification, respondents who did not identify as Democrats or Republicans were omitted, as were Democrats for Bush and Republicans for Gore. That left 140 participants for the analysis. Mean age was $32(S D=19.1)$, with $59 \%$ age 20 or under and $25 \%$ age 50 or over. The sample was predominantly female (68\%) and White (93\%). The party split was 59\% Democrat and $41 \%$ Republican, with $44 \%$ favoring Gore, $31 \%$ favoring Bush, and $25 \%$ favoring another candidate.

Paper-and-pencil questionnaires were distributed to respondents. The first questions were about the campaign: interest, candidate preferences, and commitment to their choice of candidate. Then respondents were shown one videotaped ad from each candidate then in the race. ${ }^{3}$ The ads were all positive and issue oriented and were obtained from the campaigns or taped off the air. After each ad, respondents rated the candidate in terms of his political philosophy on a scale of 1 (very liberal) to 9 (very conservative), and their favorability toward him on a scale of 1 (not at all favorable) to 10 (very favorable). They also evaluated the effects of the ad on impressions of the candidate and likelihood of voting for him for themselves, Democrats, Republicans, and the public in general. The effects questions used a scale of -3 (much less favorable/much less likely to vote for him) to +3 (much more favorable/much more likely to vote for him). ${ }^{4}$ When everyone had finished answering questions about an ad, the next one was shown. After finishing the questions about the ads, participants were asked about party identification, placement of self and target groups on the 9-point political philosophy scale, and demographic information.

Perceived effects for target groups were recoded so that for every respondent the same-party target group was the in-group and the opposite-party target group was the out-group. Effects for candidate ads were recoded along the same lines so that for every respondent the same-party candidate was the in-group candidate and the opposite-party candidate was the out-group candidate. Doing this allowed for analysis of all participants at once. It also eliminated potential inflation of results based on the artifacts of bimodal distributions in correlations. The two effects of candidate impression and voting likelihood were then averaged to form an overall effects scale for each combi- 


\section{COMMUNiCATion ReSEARCH • April 2004}

nation of candidate (2) and target group (4, including self). The alphas for the eight effects scales ranged from .71 to $.91 .^{5}$

Political distance between self and each target group was simply the absolute value of the difference between the respondent's placement of self and target group on the 9-point liberal-conservative scale. The perceived distance between candidates and target groups was calculated the same way. As with the effects measures above, each one was recorded to reflect the target groups and candidates in terms of in-group-out-group affiliations.

For distance between self and candidates, more measures were available and were incorporated. For both the in-group and the out-group candidate, a scale using the difference in ideology scores as detailed above, as well as the 10-point favorability item (reverse scored to reflect greater distance for lower favorability), a variable for candidate preference (with Bush and Gore at the poles and "other" in the middle), and a dummy variable for party affiliation was developed. Alphas for standardized scores were .85 for Gore and .86 for Bush; each candidate was classified as an in-group or out-group candidate depending on the respondent's political identification. For descriptive statistics of all the distance measures, see Table 1.

The questionnaire also assessed interest in and attention to the presidential race, intention to vote, candidate preference and commitment to that choice, age, education, race, and sex.

\section{Results}

\section{Hypothesis 1: Third-Person Effects}

Hypotheses 1a and $1 \mathrm{~b}$ predicted third-person effects for ads from the outgroup candidate. To test this, a repeated-measures MANOVA was run on the effects of the out-group ad with effects estimates on the self and progressively distant others (in-group, public, others) as the critical within-subjects factor, and party and student status as between-subjects factors. ${ }^{6}$ There was a significant main effect for the within-subjects factor $\left(F_{3,132}=89.42, p<.001, \eta^{2}=\right.$ .67), which indicated that there were significant differences in perceived effects between the target groups (including the self). A look at the means indicated a trend that is supportive of the third-person effect. Having found significant differences with an overall $F$ test and ensured a familywise error rate of $p<.05$, protected paired-sample $t$ tests employing Fisher's LSD were run.

Hypothesis 1a predicted that ads from the out-group candidate would be perceived to have greater effects on others than on the self. This was true for two of the three comparisons. See the top row of Table 2. Respondents judged 
Meirick • Dimensions of Distance

Table 1

Descriptive Statistics for Independent Variables ( $\mathrm{N}=137$ to 140)

\begin{tabular}{lcc}
\hline Variable & $M$ & $S D$ \\
\hline Self-to-group distance ${ }^{\mathrm{a}}$ & & \\
$\quad$ Self to in-group & 1.14 & 1.07 \\
$\quad$ Self to public & 2.05 & 1.47 \\
$\quad$ Self to out-group & 3.91 & 1.96 \\
Self-to-candidate distance $^{\mathrm{b}}$ & & \\
$\quad$ Self to in-group candidate & -3.16 & 1.30 \\
$\quad$ Self to out-group candidate & 3.23 & 1.44 \\
Candidate-to-group distance & & \\
$\quad$ In-group candidate to in-group & 0.95 & 1.05 \\
$\quad$ In-group candidate to public & 1.97 & 1.23 \\
$\quad$ In-group candidate to out-group & 3.83 & 1.75 \\
$\quad$ Out-group candidate to in-group & 3.93 & 1.71 \\
$\quad$ Out-group candidate to public & 2.33 & 1.24 \\
$\quad$ Out-group candidate to out-group & 1.09 & 1.47 \\
\hline
\end{tabular}

a. Self-to-group distance is the absolute value of the difference between one's own political ideology (on a 1-to-9 liberal-to-conservative scale) and the perceived ideology of the reference group. Higher scores reflect greater perceived political distance.

b. Self-to-candidate distance is the sum of $z$ scores for self-to-candidate ideological distance as explained above, candidate favorability (reverse scored), candidate preference (reverse scored), and common party affiliation with the candidate (reverse scored). Positive scores reflect distance from the candidate, negative scores indicate closeness, and 0 would indicate neutrality.

c. Candidate-to-group distance is the absolute value of the difference between the perceived ideology of the candidate and the perceived ideology of the reference group. Higher scores reflect greater perceived political distance.

themselves quite resistant, and perceived effects were significantly greater for the public and for the out-group. However, the in-group was perceived to be as resistant as the self, if not more so, to the out-group ad.

Hypothesis $1 b$ predicted that perceived effects of ads from the out-group candidate would increase as the target group became more politically distant from the self. Again, this was true for two of the three comparisons, and the self-in-group difference was the exception. In-group-public and public-outgroup differences both were significantly different at the $p<.001$ level.

\section{Hypothesis 2: First-Person Effects}

Hypothesis $2 \mathrm{a}$ and $2 \mathrm{~b}$ predicted first-person effects for ads from the in-group candidate. Again, a repeated-measures MANOVA was run with perceived effects on self, in-group, public, and out-group as a within-subjects factor and party and student status as between-subject factors. ${ }^{7}$ Again, there was a significant main effect for the within-subjects factor $\left(F_{3,132}=64.83, p<.001, \eta^{2}=\right.$ $.60)$, which indicated that there were significant differences in perceived 


\section{COMMUNiCATiOn RESEARCH • April 2004}

Table 2

Perceived Effects of Out-Group and In-Group Ads on Self and Others ( $\mathrm{N}=138$ )

\begin{tabular}{|c|c|c|c|c|c|c|c|c|}
\hline & \multicolumn{2}{|c|}{$\begin{array}{l}\text { Effect on } \\
\text { Self }\end{array}$} & \multicolumn{2}{|c|}{$\begin{array}{l}\text { Effect on } \\
\text { In-Group }\end{array}$} & \multicolumn{2}{|c|}{$\begin{array}{l}\text { Effect on } \\
\text { Public }\end{array}$} & \multicolumn{2}{|c|}{$\begin{array}{l}\text { Effect on } \\
\text { Out-Group }\end{array}$} \\
\hline & $M$ & $S D$ & $M$ & $S D$ & $M$ & $S D$ & $M$ & $S D$ \\
\hline $\begin{array}{l}\text { Out-group ad } \\
\text { In-group ad }\end{array}$ & $\begin{array}{r}-0.79_{\mathrm{a}} \\
0.68_{\mathrm{b}}\end{array}$ & $\begin{array}{l}1.32 \\
0.98\end{array}$ & $\begin{array}{l}-0.89_{\mathrm{a}} \\
1.09_{\mathrm{a}}^{* * * * *}\end{array}$ & $\begin{array}{l}1.11 \\
0.87\end{array}$ & $\begin{array}{l}0.10_{b} * * * * \\
0.81_{b} *\end{array}$ & $\begin{array}{l}1.10 \\
0.81\end{array}$ & $\begin{array}{r}1.00_{\mathrm{c}} * * * * \\
-0.42_{\mathrm{c}}{ }^{* * * *}\end{array}$ & $\begin{array}{l}0.97 \\
0.95\end{array}$ \\
\hline
\end{tabular}

Note. Scores are scale means for perceived effects of positive ads on favorability toward the candidate and likelihood of voting for him. The scale ranges from -3 to +3 . Groups with means significantly different from the self are indicated by asterisks. Within each row, groups with different subscripts are significantly different at $p<.05$.

$* p<.10 . * * * * p<.001$.

effects between the groups. With that established, protected paired $t$ tests were run.

Hypothesis $2 \mathrm{a}$ had predicted that ads from the in-group candidate would be perceived to have greater effects on the self than on others. However, this was true only for the self-out-group comparison. See the bottom row of Table 2 . In fact, the in-group was perceived to be significantly more affected than the self, whereas perceived effects for the public were greater than effects on the self to a marginally significant degree.

Hypothesis $2 \mathrm{~b}$ had predicted that perceived effects of ads from the ingroup candidate would decrease as the target group became more politically distant from the self. This was true for two of the three comparisons. Perceived effects on the out-group were significantly smaller than those on the public, which were in turn significantly smaller than those on the in-group. But as noted above, effects in the in-group were greater than those on the self.

\section{Hypothesis 3: Self-Target Distance}

This set of hypotheses dealt with distance between the self and each target group. The analysis here consists of partial correlations of the posited relationships, with the influence of party and student status removed. See the top rows of Table 3.

Hypothesis 3a predicted a positive relationship between self-target political distance and the perceived effects of out-group ads on each group. However, this hypothesis received no support; none of the three coefficients reached significance, and two were negative in sign. Hypothesis $3 \mathrm{~b}$ predicted a negative relationship between self-to-target political distance and perceived effects of the in-group ads on each group. As with Hypothesis $3 a$ above, there was no support for this hypothesis. Although two of the coefficients had the predicted signs, they all fell well shy of significance. 
Meirick • Dimensions of Distance

Table 3

Partial Correlations Between Political Distance and Perceived Effects ( $\mathrm{N}=132)$

\begin{tabular}{|c|c|c|c|c|}
\hline Dimension of Distance & $\begin{array}{l}\text { Effect on } \\
\text { Self }\end{array}$ & $\begin{array}{l}\text { Effect on } \\
\text { In-Group }\end{array}$ & $\begin{array}{c}\text { Effect on } \\
\text { Public }\end{array}$ & $\begin{array}{l}\text { Effect on } \\
\text { Out-Group }\end{array}$ \\
\hline \multicolumn{5}{|l|}{ Self-to-group distance } \\
\hline In-group ad & $N A$ & -.06 & .02 & .04 \\
\hline Out-group ad & $N A$ & -.12 & -.03 & .07 \\
\hline \multicolumn{5}{|l|}{ Self-candidate distance } \\
\hline In-group ad & $-.33 * * * *$ & $-.36 * * * *$ & $-.28 * * *$ & -.13 \\
\hline Out-group ad & $-.29 * * *$ & $-.27 * * *$ & $-.22 * * *$ & -.04 \\
\hline \multicolumn{5}{|l|}{ Candidate-group distance } \\
\hline In-group ad & $N A$ & .03 & -.01 & $-.17 * *$ \\
\hline Out-group ad & $N A$ & -.13 & $-.26 * * *$ & -.14 \\
\hline
\end{tabular}

Note. $N A=$ not applicable. Partial correlations control for respondent's party identification and student status.

$* * p<.05 . * * * p<.01 . * * * p<.001$.

\section{Hypothesis 4 and Research Question 1:}

\section{Self-Candidate Distance}

This set of hypotheses deals with the relationship between self-to-candidate political distance and perceived effects on self, in-group, and out-group, whereas the research question concerns effects on the public. As with the third set of hypotheses, the analysis will rely on partial correlations controlling for party and student status. See the middle rows of Table 3.

Hypothesis 4a predicted that the greater the distance between the self and a candidate, the smaller the effects on the self. This was the case both for the in-group candidate $(r=-.33, p<.001)$ and the out-group candidate $(r=-.29$, $p<.01$ ). Hypothesis $4 \mathrm{~b}$ predicted a similar relationship for perceived effects on the in-group, and this hypothesis also found support for both the in-group candidate $(r=-.36, p<.001)$ and the out-group candidate $(r=-.27, p<.01)$.

The reverse relationship was expected for Hypothesis $4 \mathrm{c}$ such that greater self-candidate distance would be reflected in greater perceived effects on the out-group. However, this hypothesis found no support. Coefficients were negative and nonsignificant.

Given dueling theories and evidence, the question of the relationship between self-candidate distance and perceived effects on the public was left as the first research question. The results provide a relatively unequivocal answer to the question: The greater the distance between self and candidate, the smaller the perceived effects on the public, both for the in-group candidate $(r=-.28, p<.01)$ and the out-group candidate $(r=-.22, p<.01)$. 


\section{COMMUNiCATion RESEARCH • April 2004}

\section{Hypothesis 5: Candidate-Target Group Distance}

This hypothesis addresses the question of the inferred distance between candidates and target groups. It predicts that the greater the perceived candidate-to-group distance, the smaller the perceived effects of the candidate's ad on the group. Two analysis strategies are used here. The first, as above, examines partial correlations for each target group. The second looks at the bigger picture, examining the correlation between the mean candidateto-group distances and mean perceived effects for each combination of candidate and target group.

Correlations by target group were negative for five of the six cases but significant for only two. See the bottom rows of Table 3. The first was the relationship between in-group-candidate-to-out-group distance and effects of the in-group candidate's ad on the out-group $(r=-.17, p<.05)$; the second was out-group-candidate-to-public distance and effects of that candidate's ad on that group $(r=-.26, p<.01)$.

The bigger picture looks at relationships across the target groups instead of just within them. Although this analysis relies on an $N$ of 6 (3 Target Groups $\times 2$ Candidates), the pattern is clear: As candidate-target-group distances increase, perceived effects on the groups decrease $(r=-.97, p=.002)$.

\section{Research Question 2}

The second research question asks how much variance the alternate measures of distance account for in perceived effects on target groups. To answer this question, self-to-candidate, self-to-target-group and candidate-to-targetgroup distance were regressed on perceived effects of in-group and out-group ads for each target group in six separate hierarchical multiple regressions. In addition to the three measures of political distance between self, target groups, and candidates, the regression equation also controlled for the impact of four dichotomous variables: sex, race (White vs. minority), party, and student status. Final betas are in Table $4 .^{8}$

Self-to-candidate distance had significant betas in five of the six cases (and a marginally significant one for the other case), and all coefficients were negative, indicating an inverse relationship between self-candidate distance and perceived effects on the target groups. Self-to-group distance, the individual-level measure of the traditional conception of social distance, was significantly and positively related to perceived effects of the out-group ad on the public and the out-group, as would be expected, but not in other cases. Perceived distance between candidate and target group had only one 
Meirick • Dimensions of Distance

Table 4

Regressions of Political Distance Measures on Perceived Effects ( $\mathrm{N}=137$ to 138)

\begin{tabular}{|c|c|c|c|c|c|c|}
\hline \multirow[b]{2}{*}{$\begin{array}{l}\text { Dimension } \\
\text { of Distance }\end{array}$} & \multicolumn{2}{|c|}{$\begin{array}{l}\text { Effect on } \\
\text { In-Group }\end{array}$} & \multicolumn{2}{|c|}{$\begin{array}{c}\text { Effect on } \\
\text { Public }\end{array}$} & \multicolumn{2}{|c|}{$\begin{array}{l}\text { Effect on } \\
\text { Out-Group }\end{array}$} \\
\hline & $\begin{array}{l}\text { In- } \\
\text { Group } \\
\text { Ad }\end{array}$ & $\begin{array}{c}\text { Out- } \\
\text { Group } \\
\text { Ad }\end{array}$ & $\begin{array}{l}\text { In- } \\
\text { Group } \\
\text { Ad }\end{array}$ & $\begin{array}{l}\text { Out- } \\
\text { Group } \\
\text { Ad }\end{array}$ & $\begin{array}{l}\text { In- } \\
\text { Group } \\
\text { Ad }\end{array}$ & $\begin{array}{l}\text { Out- } \\
\text { Group } \\
\text { Ad }\end{array}$ \\
\hline \multicolumn{7}{|c|}{ Self to group } \\
\hline$\beta$ & .06 & -.08 & .04 & $.25^{* *}$ & .04 & $.28^{* * *}$ \\
\hline$R^{2} \Delta$ & .00 & .01 & .00 & .01 & .00 & .02 \\
\hline \multicolumn{7}{|c|}{ Self to candidate } \\
\hline$\beta$ & $-.43^{* * * * *}$ & $-.26^{* *}$ & $-.30 * * *$ & $-.32^{* *}$ & $-.17^{*}$ & $-.27 * *$ \\
\hline$R^{2} \Delta$ & $.13^{* * * * *}$ & $.05^{* * * *}$ & $.07 * * *$ & $.08 * * * *$ & .02 & $.03^{* *}$ \\
\hline \multicolumn{7}{|c|}{ Candidate to group } \\
\hline$\beta$ & .01 & .01 & -.04 & -.07 & $-.20 *$ & .09 \\
\hline$R^{2} \Delta$ & .00 & .00 & .00 & .00 & $.03 *$ & .01 \\
\hline
\end{tabular}

Note. This table reports the results of six separate hierarchical regressions to predict perceived effects of each ad on each group of others. These coefficients show variance accounted for over and above that of a previous block of demographic data (sex, race, party affiliation, and student status). Betas are from the final regression equation, while $R^{2} \Delta$ is in comparison with variance accounted for by the previous block(s).

${ }^{*} p<.10 .{ }^{* *} p<.05 .{ }^{* * *} p<.01 .{ }^{* * * *} p<.001$.

coefficient of interest, a marginal negative relationship with effects of the ingroup ad on the out-group.

\section{Discussion}

The results here provide support for using topic-relevant reference groups in third-person effect research. The strongest third-person effect for the outgroup candidate's ad in Hypothesis 1a and the strongest (and only) firstperson effect for the in-group candidate's ad in Hypothesis 2 a was found for the out-group, the most politically distant group; not for the public in general, the most geographically distant or most generalized group.

The third-person effect for the a priori "undesirable message," the outgroup candidate ad, was robust as usual in Hypothesis 1a, except for the self-in-group comparison. It is not unusual to find a nonsignificant difference in effects between the self and the closest target group. Somewhat more surprising was the self-in-group difference for in-group candidate ads; a firstperson effect was predicted in Hypothesis 2a, but the in-group was perceived as significantly more influenced than the self (as was the public, to a marginally significant degree). If a message is desirable, we might expect that people would perceive it to have the greatest, most "optimal impact" on themselves 


\section{COMMUNiCATion ReSEARCH • April 2004}

(Hoorens \& Ruiter, 1996). But Duck et al. (1995) had a finding similar to that of the present research. They attributed it to "a general disinclination to admit personal persuasibility" (p. 212) even for desirable content, a phenomenon also described by Gunther and Mundy (1993). As in this study, Duck et al. saw people admitting influence from pro-in-group material-just to a lesser extent than the in-group and the public. The self can then claim a moderate amount of beneficial influence from a desirable message while still maintaining a perception of relative impersuasibility and self-determination.

As for the different measures of distance between self, target group and communicator, the strongest results were for self-to-candidate distance, which was considered analogous to message desirability. In support of Hypotheses $4 \mathrm{a}$ and $4 \mathrm{~b}$, it was found that self-candidate distance was negatively related to perceived effects on self and the in-group such that the closer you are to a candidate, the greater the perceived effects of his ad on yourself and your in-group. Research Question 1 found that this relationship also extends to the public.

There is a new wrinkle here, however, that can be seen in the null findings for Hypothesis 4c, which had predicted a positive relationship between selfcandidate distance and perceived effects on out-groups on the assumption that it is self-enhancing to contrast out-group responses with your own: The more you love your candidate, the more you would think the out-group would hate him, and the more you hate the opposing candidate, the more you would think the out-group would love him. There, the coefficients were negative (as they were for self, in-group, and public) and nonsignificant. The results from Research Question 2 showed significant negative relationships between selfcandidate distance and perceived effects of both candidates' ads on the outgroup. It seems that the closer you are to a candidate, the more you think everybody, even the other party, will respond positively to him or her.

The findings for the other new distance measures were slim. Political distance between self and target groups had no significant correlations with perceived effects on the groups, so Hypothesis $3 \mathrm{~b}$ and Hypothesis $3 \mathrm{~d}$ found no support. Self-group distance did show significant betas in two of the six regression equations run in Research Question 2 that suggested greater distance from the out-group and the public would be related to greater effects of the out-group candidate's ad on those two groups. This relationship is consistent with the social distance corollary, and the conditions under which is it found are the conditions under which the social distance corollary would most obtain, but it is relatively scant evidence.

The inferred distance between candidate and group did not fare much better. Candidate-group distance had significant partial correlations in two of the six tests; when self-candidate and self-group distance were added into 


\section{Meirick • Dimensions of Distance}

the equation, only one relationship remained marginally significant. It was an important case, however, one that may help to explain why a first-person effect was found for the out-group in Hypothesis 2a. In addition, the acrossgroup correlation showed that as perceived distance between candidate and groups increased, perceived effects of the ads on groups decreased $(r=-.97$, $p<.01)$.

If we take the findings of the regression equations at face value, they suggest that people's estimates of media effects on others are not based on inferences they make about the relationship between the target group and the communicator, based on their real-world knowledge or expectations. Nor do their estimates strongly reflect their own relationships with the target groups, as the social distance corollary and social identity theory would predict. Instead, their estimates reflect their own relationship with the communicator, regardless of whether the target group is an in-group, an out-group, or somewhere in between.

This is not an unconditional triumph for the self-enhancement explanation for third-person effects. First, to the extent that self-esteem is derived from social identity, we would have expected self-group distance to have a greater role in perceived effects on others. Second, we would have expected the relationship between self-candidate distance and perceived effects to be different for out-groups than for in-groups, and it was not. The findings are more consistent with the false consensus effect, though make no mistake, this is not the false consensus effect per se. People's responses to political ads had opposite signs and were significantly different from the responses they thought others of the opposing party would have. But it seems that in examining perceived effects on one target group at a time, your own distance from the candidate flavors your perceptions of how that group will respond.

It might be premature to write off self-group and group-communicator distance. First, it may be that looking at the effect of distance within a target group minimizes the effect of distance and ignores between-group differences. The across-group correlation between group-candidate distance and perceived effects suggests as much. Indeed, mean self-group distance and mean perceived effects on the corresponding groups show similar coefficients for both desirable $(r=-.997, p=.05, n=3)$ and undesirable messages $(r=.975$, $p=.14, n=3$ ), although the $n$ 's become prohibitively small.

The other reason not to write off self-group and candidate-group distances is that this study has three key limitations. First, this study's measures of these distances were limited to the differences between single-item ideology measures, whereas the measure of self-candidate distance also included three other items in a reliable scale. More reliable measures of self-group and group-candidate differences might reduce measurement error and find 


\section{COMMUNiCATion RESEARCH • April 2004}

something where this study did not. The second key limitation is the relatively small $N$, which may have made it difficult to find significant relationships if they, in fact, exist. Third, it should also be stressed that the convenience sample employed here means that one should use caution in making generalizations from this study. Other limitations of this study include a small number of ads that cannot be claimed to be representative of all current political advertising and a lack of perceived exposure measures that could have accounted for another potential influence on perceived effects.

Future research addressing these limitations could investigate not only the viability of topic-relevant reference groups but also of topic-relevant measures of distance between self, reference groups, and communicators. These measures could help shed light on the mechanisms underlying the thirdperson effect, particularly if they are used in conjunction with experimental manipulations to enhance self-enhancement or accuracy motivations in forming estimates of media effects on others. Survey researchers could advance this cause as well by developing measures of the motivations that people have in estimating the effects of different messages. Such an approach would dovetail nicely with Peiser and Peter's (2001) limits/possibilities perspective, which argues for the integration of the self-enhancement view with the accuracy view. People, they argue, "may want to present themselves in a most positive light, but they will succeed only to the extent that their perceptual position—or, more generally, reality_permits" (Peiser \& Peter, 2001, p. 175). Moreover, this approach could revive the question of accuracy of third-person perceptions (Cohen et al., 1988; Gunther, 1991) by suggesting what relationships (self-group, self-communicator, communicator-group) are factoring into people's estimates of media effects and what motivations those relationships represent.

\section{Notes}

1. An earlier version of this article was presented to the Communication Theory and Methodology Division, 2000 Association for Education in Journalism and Mass Communication Convention, Phoenix, Arizona.

2. Admittedly, it is possible that people have a lay theory of selective exposure similar to the lay theory that they appear to have about hypodermic media effects (Eveland, Nathanson, Detenber, \& McLeod, 1999). And if so, people might expect Republicans, for example, to tune in to the Republican National Convention and avoid the Democratic National Convention. However, exposure to political ads would not appear to present the same opportunity for selective exposure because they appear without warning during nonpartisan news and entertainment programs. People might expect political junkies in general to see more political ads because they watch more news and public affairs programming, where more political ads appear. But would they expect more 


\section{Meirick • Dimensions of Distance}

Democratic versus Republican political junkies to watch—or more Republican versus Democratic candidates to advertise? It seems unlikely.

3. The League of Women Voters (LWV) group, which participated in the study on January 11, 2000, was shown ads for John McCain, George W. Bush, and Bill Bradley; they read transcripts of ads for $\mathrm{Al}$ Gore and Steve Forbes because taped ads were not yet available. The Gore taped ad subsequently shown to the other groups was similar in theme but not identical to the transcript. The Republican caucus group was shown ads for Gore, Bush, Bradley, and McCain on March 7. The student group on March 21 saw ads for Gore and Bush only. The analyses rely on each group's responses to the Gore and Bush ads. Order was rotated for the LWV and the student samples, but no order effects were found.

4. Note that the scale allows for positive and negative reactions to messages, in addition to no change. An opposing party candidate's message may reveal unpalatable issue positions or a halting style of delivery that prompt unfavorable reaction. Similarly, an opposing candidate's argument may prompt resistance through counterarguing, which tends to reinforce one's original position (Zaller, 1991). In any case, it seems unwarranted to assume change in only a positive direction; Cohen and Davis (1991) used a similar 7-point bipolar scale. Change in a positive direction, the direction intended by the ad, is what the hypotheses address.

5 . The alphas were as follows. For in-group candidate ad: effects on self, .76; on ingroup, .75; on public, .71; on out-group, .74. For out-group candidate ad: effects on self, .84 ; on in-group, .81; on public, .91; on out-group, .71.

6. Both party $\left(F_{1,134}=42.82, p<.001, \eta^{2}=.24\right)$ and student status $\left(F_{1,134}=27.28\right.$, $p<.001, \eta^{2}=.17$ ) had significant main effects such that Democrats and nonstudents perceived smaller effects on average. These factors also had two-way interactions with each other and with the within-subjects factor such that Democrats and nonstudents (and especially nonstudent Democrats) perceived smaller effects on self, in-group, and the public (but not the out-group) from the out-group ad than did Republicans and students. But the within-subject factor differences remained robust across these subgroups of partisanship and student status.

7. There was a main effect for student status $\left(F_{1,134}=4.04, p<.05, \eta^{2}=.03\right)$ such that nonstudents perceived greater effects on average. Student status and party interacted such that Republican nonstudents and Democratic students perceive greater effects on average. And party and student status each interacted with the withinsubjects factor such that Democrats and students perceived greater effects on themselves, in-group, and public from in-group ads than did Republicans and nonstudents, and Democrats also perceived smaller effects on out-groups than did Republicans. But as with Hypothesis 1, the within-subject factor differences remained relatively stable across these subgroups of partisanship and student status.

8. Multicollinearity does not present a major problem in these regression analyses. In four of the six analyses, tolerance statistics were .60 or greater. In the other two, the lowest tolerance statistic was .42 in the out-group ad effects on out-groups equation and .54 in the out-groups ad effects on public equation. All of these are above the common tolerance cutoff of .25 .

\section{References}

Chapin, J. R. (2000). Not like me: Self vs. other distinctions in first-person perception. Communication Research Reports, 17, 320-330. 


\section{COMMUNiCATiOn RESEARCH • April 2004}

Christen, C. T., \& Gunther, A. C. (2003). The influence of mass media and other culprits on the projection of personal opinion. Communication Research, 30, 414-431.

Clement, R. W., \& Krueger, J. (2002). Social categorization moderates social projection. Journal of Experimental Social Psychology, 38(3), 219-231.

Cohen, J., \& Davis, R. G. (1991). Third-person effects and the differential impact in negative political advertising. Journalism Quarterly, 68, 680-688.

Cohen, J., Mutz, D., Price, V., \& Gunther, A. (1988). Perceived impact of defamation: An experiment on third person effects. Public Opinion Quarterly, $52,161-173$.

Davison, W. P. (1983). The third-person effect in communication. Public Opinion Quarterly, 47, 1-15.

Downs, A. (1957). An economic theory of democracy. New York: Harper \& Row.

Duck, J. M., Hogg, M. A., \& Terry, D. J. (1995). Me, us, and them: Political identification and the third person effect in the 1993 Australian federal election. European Journal of Social Psychology, 25, 195-215.

Eveland, W. P., Nathanson, A. I., Detenber, B. H., \& McLeod, D. M. (1999). Rethinking the social distance corollary: Perceived likelihood of exposure and the third-person perception. Communication Research, 26, 275-302.

Gibbon, P., \& Durkin, K. (1995). The third person effect: Social distance and perceived media bias. European Journal of Social Psychology, 25, 597-602.

Gunther, A. C. (1991). What we think others think: Cause and consequence in the third person effect. Communication Research, 18, 355-372.

Gunther, A. C., \& Christen, C. T. (2002). Projection or persuasive press? Contrary effects of personal opinion and perceived news coverage on estimates of public opinion. Journal of Communication, 52(1), 177-195.

Gunther, A. C., Christen, C. T., Liebhart, J. L., \& Chia, S. C. (2001). Congenial public, contrary press and biased estimates of the climate of opinion. Public Opinion Quarterly, 65(3), 295-320.

Gunther, A. C., \& Mundy, P. (1993). Biased optimism and the third-person effect. Journalism Quarterly, 70(1), 58-67.

Hoorens, V., \& Ruiter, S. (1996). The optimal impact phenomenon: Beyond the third person effect. European Journal of Social Psychology, 26, 599-610.

Innes, J. M., \& Zeitz, H. (1988). The public's view of the impact of the mass media: A test of the 'third person' effect. European Journal of Social Psychology, 18, 457-463.

Jones, E. E. (1979). The rocky road from acts to dispositions. American Psychologist, 34, 104-117.

Marks, G., \& Miller, N. (1987). Ten years of research on the false consensus effect: An empirical and theoretical review. Psychological Bulletin, 102, 72-90.

Meirick, P. C. (2002). Self-enhancement, self-affirmation and threats to selfworth: Three tests of a motivational explanation for first- and thirdperson effects. Dissertation Abstracts International, 63(6), 2037. (UMI No. 3056339)

Neuwirth, K., \& Frederick, E. (2002). Extending the framework of third, first and second-person effects. Mass Communication and Society, 5(2), 113141. 


\section{Meirick • Dimensions of Distance}

Neuwirth, K., Frederick, E., \& Mayo, C. (2002). Person-effects and heuristicsystematic processing. Communication Research, 29(3), 321-360.

Peiser, W., \& Peter, J. (2001). Explaining individual differences in thirdperson perception: A limits/possibilities perspective. Communication Research, 28, 156-180.

Perloff, R. M. (1989). Ego-involvement and the third person effect of televised news coverage. Communication Research, 16, 236-262.

Perloff, R. M. (1999). The third-person effect: A critical review and synthesis. Media Psychology, 1, 353-378.

Tajfel, H., \& Turner, J. C. (1979). An integrative theory of intergroup conflict. In W. G. Austin \& S. Worchel (Eds.), The social psychology of intergroup relations (pp. 33-47). Monterey, CA: Brooks/Cole.

Taylor, S. E., \& Brown, J. D. (1988). Illusion and well-being: A social psychological perspective on mental health. Psychological Bulletin, 103, 193-210.

Taylor, S. E., \& Brown, J. D. (1994). "Illusion" of mental health does not explain positive illusions. American Psychologist, 49, 972-973.

Turner, J. C. (1985). Social categorization and the self-concept: A social cognitive theory of group behavior. In E. J. Lawler (Ed.), Advances in group processes (Vol. 2, pp.77-121). Greenwich, CT: JAI.

Vallone, R. P., Ross, L., \& Lepper, M. R. (1985). The hostile media phenomenon: Biased perception and perceptions of media bias in coverage of the Beirut massacre. Journal of Personality and Social Psychology, 49, 577585.

Wan, F. (2002). The impact of idealized images in advertising. Dissertation Abstracts International, 62(12), 3982. (UMI No. 3037494)

White, H.A. (1997). Considering interacting factors in the third-person effect: Argument strength and social distance. Journalism and Mass Communication Quarterly, 74(3), 557-564.

White, H. A., \& Dillon, J. F. (2000). Knowledge about others' reaction to a public service announcement: The impact of self-persuasion and third-person perception. Journalism and Mass Communication Quarterly, 77(4), 788803.

Zaller, J. (1991). Information, values, and opinion. American Political Science Review, 85(4), 1215-1237.

Patrick C. Meirick (Ph.D., University of Minnesota, 2002) is an assistant professor in the Department of Communication at the University of Oklahoma. His research interests include media effects, political communication, and social cognition. He is currently conducting research on the third-person effect's target corollary and on the role of political knowledge in responses to negative advertising. 